\title{
RADIOCARBON AND ARCHAEOLOGY IN JAPAN AND KOREA: WHAT HAS CHANGED BECAUSE OF THE YAYOI DATING CONTROVERSY?
}

\author{
Shin’ya Shoda \\ National Research Institute for Cultural Properties, Nara 94-1 Kinomoto, Kashihara, Nara 634-0025, Japan. \\ Email: shoda@nabunken.go.jp.
}

\begin{abstract}
Since the sensational 2003 announcement that pushed the start of the Yayoi period back by 500 yr, archaeologists working on 1st millennium BC material from northeast Asia have had to switch from the older short chronology to a new long chronology. However, this change need not apply to the entire northeast Asian region as China's chronology is tied to written records. The timeline of the Korean peninsula, intermediate between the Chinese and Japanese ones, needs to be reexamined. The chronology of the 1st millennium BC in the Korean peninsula is still in dispute, in part because many of the radiocarbon dates lack clear archaeological contexts. This paper shows that a reliable typological relationship observed in archaeological materials existed at this time linking northeast Asia from China to Japan. This paper includes absolute dates based on the initial AMS ${ }^{14} \mathrm{C}$ measurements of charred crops from South Korean sites.
\end{abstract}

\section{INTRODUCTION}

One of the characteristics of the practice of Japanese archaeology is the detailed chronological study of pottery. Before the application of radiocarbon dating, Japanese archaeology had established a prehistoric chronology that was detailed enough for questions to be raised about the reliability of ${ }^{14} \mathrm{C}$ dating at that time (Sahara 1981). Since the author has already reviewed the application of ${ }^{14} \mathrm{C}$ dating in Japanese archaeology and the Yayoi dating controversy (Shoda 2007), this paper discusses what has changed, or will change, because of this controversy.

The Yayoi period is defined as the earliest food production by paddy field in the majority of the Japanese islands (Sahara 1975). During this period, people also began to use metal. The introduction of irrigated paddy field technology from the outside seemed to change subsistence strategies drastically and triggered the formation of complex societies in Japan. The sensational 2003 announcement (Harunari et al. 2003) by the National Museum of Japanese History (hereafter NMJH) based on accelerator mass spectrometry (AMS) ${ }^{14} \mathrm{C}$ dating of charred remains on pottery, pushed the start of the Yayoi period back by $500 \mathrm{yr}$, and triggered a vigorous debate concerning the reexamination of traditional dating. Although the traditional chronology of the Yayoi period sets its beginning in the 5th or 4th century BC, the new chronology presented by the NMJH (Harunari et al. 2003) suggests the period began as early as the 10th century BC. Some contrary opinions were presented to this drastic change, and the discussion is still ongoing: Shoda (2006) advocated that, even though the traditional dating should be corrected, the Yayoi cannot begin so early considering comparative dates from the rest of northeast Asia. Mizunoe (2009) pointed out that the NMJH (Nishimoto 2007; Fujio 2007) would be changing the definition of assemblages themselves by applying the newer ${ }^{14} \mathrm{C}$ dating. Additionally, Miyaji (2009) noted that misidentifications of each pottery type within each assemblage lead to their being dated $100 \mathrm{yr}$ older than they should be.

However, by now most Japanese archaeologists, including myself, have basically accepted this shift to varying degrees. Yet, this change need not apply to the entire northeast Asian region, particularly as China's chronology for the 1st millennium BC is tied to written records via Zhou Dynasty inscribed bronze ware, as well as many AMS ${ }^{14} \mathrm{C}$ data (Xia-Shang-Zhou Dating Project Group 2000). Furthermore, adopting the long chronology in peripheral areas means denying the traditional inclined chronology, i.e. the idea that archaeological artifacts from the center are considered to be older while those from peripheral areas would be younger (Onuki 2003:42). This situation seem-

(C) 2010 by the Arizona Board of Regents on behalf of the University of Arizona Proceedings of the 20th International Radiocarbon Conference, edited by A J T Jull RADIOCARBON, Vol 52, Nr 2-3, 2010, p 421-427 
ingly resembles that of the 2nd radiocarbon revolution in Europe (Renfrew 1973:94), but the diffusionist framework itself does not need to be thrown out entirely in northeast Asia, because agriculture and metallurgy were clearly introduced to the Korean peninsula and Japanese islands from the northeast Asian continent. What we need to reexamine is the assumptions underlying this inclined chronology.

\section{CHRONOLOGY OF THE KOREAN PENINSULA FROM THE 2ND TO 1ST MILLENNIUM BC}

Considering the social and material links across northeast Asia, the chronology of the Korean peninsula, intermediate between that of Japan with its new long chronology and China with its textbased one, needs to be reexamined. The Korean peninsula is located between the area for which a text-based chronology exists and the Yayoi cultural area, which has no written record. Traditionally, the dating of this area depended on the bronze types shared with China, such as lute-shaped bronze daggers, which are widely distributed in northeast Asia. In South Korea, because most of the ${ }^{14} \mathrm{C}$ data lack clear archaeological contexts, typological chronologies and an absolute dating of the Bronze Age are still in dispute (Park 1999; Kim 2001; Bae 2007; HW Lee 2009; Shoda 2009a,b). On the other hand, in North Korea, there are no reliable ${ }^{14} \mathrm{C}$ data as far as we know.

The dual-line theory (according to which 2 different groups of people merged, one group from the northeast and one from the northwest part of the Korean peninsula) is thought to explain the development of the local Bronze Age society (BK Lee 1974); recent papers have altered some of the details of this process (Park 1999; Kim 2001). This theory considers an archaeological assemblage as representative of human groups, and it supports the overlapped chronology, which places various assemblages in the same time and same place.

Yet, considering the distribution of these assemblages, this coexistence theory is untenable. Different archaeological assemblages do not show the presence of different human groups, but just changes in style over time according to typological analysis (Shoda 2009a,b). Using my own chronology and comparing the ${ }^{14} \mathrm{C}$ dates with text-based dates from China, an absolute date for the Korean Bronze Age was suggested (Shoda 2009a,b). However, the date of the beginning of the Bronze Age in this area is unknown because it predates the influx of Chinese bronze. Furthermore, the boundary of the Early/Late Bronze Age lies between the 8th and 6th centuries BC, but cannot be placed more precisely due to the paucity of bronze artifacts found associated with pottery in Korea.

\section{MATERIALS AND METHODS}

Using short-lived crop remains for dating (e.g. rice) has some advantages over other materials, even though these kinds of samples are not always abundant at archaeological sites. First, the time lag between the age of the sample and the target for which we want to know the date is slight, about $1 \mathrm{yr}$. Second, these crops definitely relate to human activity when found in clear archaeological contexts. Finally, given good preservation, the plant materials can be identified, meaning we can know what we are measuring, without concern for the marine reservoir effect. Moreover, they are direct evidence of agriculture, one of the crucial technological developments of this period.

An initial test was run in the Paleo Labo Co. Ltd laboratory (Kiryu, Gunma, Japan) at the author's request. Charred rice grain samples were collected from 3 sites in South Korea (Figure 1): Gyodong dwelling pit 1 (Baek et al. 2002), belonging to the middle Early Bronze Age; Songdamri dwelling pit KC-001 of the late Early Bronze Age (Korean Institute for Archaeology and Environment 2008); and Jagaeri dwelling pit 48 (Na 2006), belonging to the 1st phase of the Late Bronze Age. These 3 samples all have clear archaeological contexts, having been excavated from the floor layer of dwell- 
ing pits of which we can identify the chronological phase from the structure of the dwelling pit itself and from the associated pottery. The results are $2860 \pm 20$ BP (PED-11437) for Gyodong dwelling pit 1, $2720 \pm 20$ BP (PED-11435) for Songdamri dwelling pit KC-001, and $2480 \pm 20$ BP (PED11436) for Jagaeri dwelling pit 48, respectively (Table 1). These data correspond with the chronology developed by the author (Figure 2).

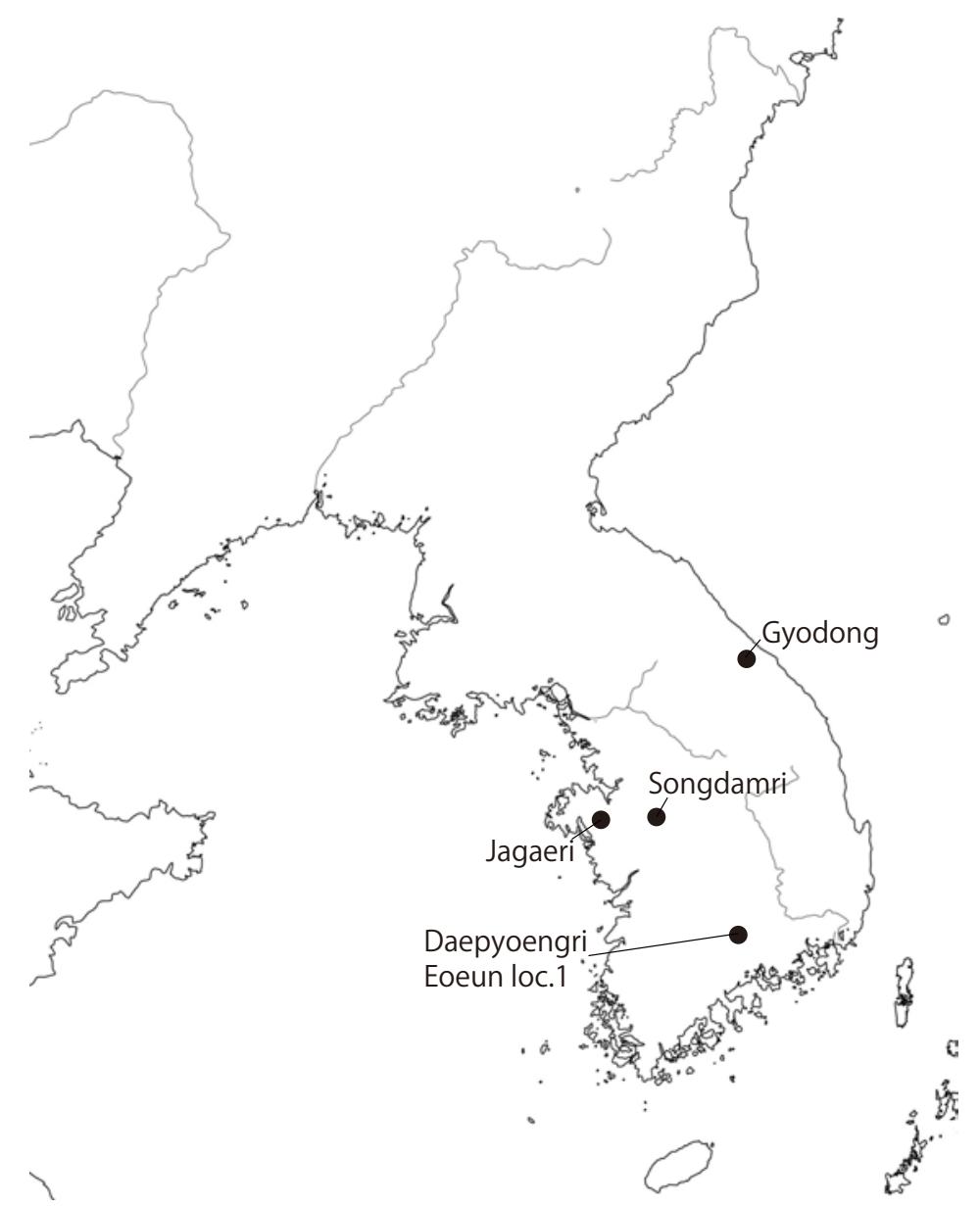

Figure 1 Region of northeast Asia and the archaeological sites referred in this paper

Table 1 AMS ${ }^{14} \mathrm{C}$ dates of charred rice samples from Bronze Age Korea.

\begin{tabular}{|c|c|c|c|c|c|c|}
\hline Site & Phase & $\mathrm{Nr}$ & $\delta^{13} \mathrm{C}$ & ${ }^{14} \mathrm{C}$ date & Age range $\mathrm{BC} 1 \sigma$ & Age range $\mathrm{BC} 2 \sigma$ \\
\hline $\begin{array}{l}\text { Gyodong, } \\
\text { Dwelling pit } 1\end{array}$ & $\begin{array}{l}\text { Middle Early } \\
\text { Bronze }\end{array}$ & $\begin{array}{l}\text { PED-11437, } \\
\text { No.:S-6 }\end{array}$ & $-26.17 \pm 0.11$ & $2860 \pm 20$ & 1060 (68.2\%) 970 & $\begin{array}{r}1120(90.0 \%) 970 \\
960(5.4 \%) 930\end{array}$ \\
\hline $\begin{array}{l}\text { Songdamri, } \\
\text { Dwelling pit } \\
\text { KC-001 }\end{array}$ & $\begin{array}{l}\text { Late Early } \\
\text { Bronze }\end{array}$ & $\begin{array}{l}\text { PED-11435, } \\
\text { No.:S-4 }\end{array}$ & $-27.88 \pm 0.13$ & $2720 \pm 20$ & 895 (68.2\%) 830 & 910 (95.4\%) 815 \\
\hline $\begin{array}{l}\text { Jagaeri, } \\
\text { Dwelling pit } \\
48\end{array}$ & $\begin{array}{l}\text { Early Late } \\
\text { Bronze }\end{array}$ & $\begin{array}{l}\text { PED-11436, } \\
\text { No.:S-5 }\end{array}$ & $-25.89 \pm 0.19$ & $2480 \pm 20$ & $\begin{array}{l}760(12.2 \%) 720 \\
700(3.0 \%) 680 \\
670(24.8 \%) 610 \\
600(28.1 \%) 540\end{array}$ & 770 (95.4\%) 510 \\
\hline
\end{tabular}




\section{DISCUSSION}

Figure 2 shows the chronology of the 2nd and 1st millennium BC in northeast Asia based on the author's previous studies (Shoda 2009a,b). China already had written records by this time, and typological dating is also connected with recorded ages such as the Shang, Western Zhou, etc., based on the inscribed bronze wares and written documents. There are also many AMS ${ }^{14} \mathrm{C}$ dates (Xia-ShangZhou Dating Project Group 2000). Since comparative dating between China and the Korean peninsula is mainly based on the typology of bronze wares, direct comparisons with ${ }^{14} \mathrm{C}$ data cannot be made, but we can roughly compare written records to calibrated dates. On the other hand, the comparative chronology relating South Korea to Japan is highly developed, based on the comparativetypological studies of pottery and stone tools in both areas, and shows the beginning of the Yayoi located near the beginning of the Korean Late Bronze Age (Fukasawa and Shoda 2009).

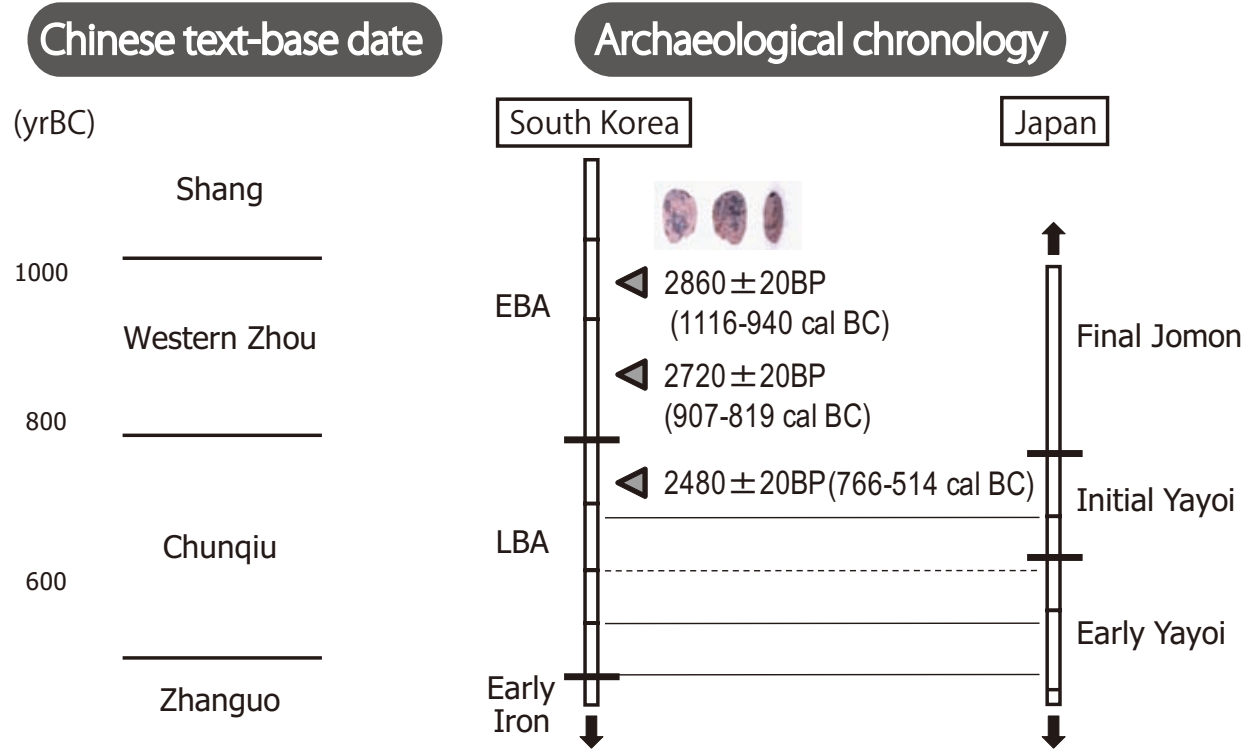

Figure 2 Contrasting the textual and material chronologies with the addition of ${ }^{14} \mathrm{C}$ dates

By inserting the ${ }^{14} \mathrm{C}$ date of charred rice into this relative chronology, we can also suggest the date of the Initial Yayoi. As mentioned above, the beginning of the Yayoi was placed in the 10th century BC by NMJH (Harunari et al. 2003; Fujio 2007; Nishimoto 2007), but, considering the above-mentioned ${ }^{14} \mathrm{C}$ data of charred rice, it shifts to between $907-819$ and 766-514 cal BP, about $150 \mathrm{yr}$ younger than the NMJH proposed. Furthermore, the author (Shoda 2006) has posited, based on comparisons with written records, that the start of the Yayoi cannot extend back to the 10th century $\mathrm{BC}$. The result ${ }^{14} \mathrm{C}$ dating of the charred rice also shows that the period seems to be younger than suggested by the NMJH (Harunari et al. 2003). It is unclear whether this discrepancy results from differences in the dating material (crops vs. charred remains on pottery) or from some other errors. Because the number of dated samples is not large enough to discuss this problem further, a solution may only be revealed after further study.

Archaeologists will now want to know how the timing of our prehistories will change because of the adoption of the long chronology in Yayoi dating, particularly, when the 2 characteristic technologies of the Yayoi period (wet rice production and metallurgy) appeared. First, the adoption of rice agri- 
culture in South Korea occurred at the beginning of the Bronze Age in this area. There are 2 sites with very old dates for early agricultural evidence (Figure 1), including Daepyoeng-ri Eoeun locality 1 for which 1 date has been reported by Crawford and Lee (2003). However, this date has too wide a range of uncertainty. Other data of charred rice and millet presented by SK Lee (1999) from the same dwelling pit of Daepyoeng-ri Eoeun locality 1 suggests more reliable and younger ${ }^{14} \mathrm{C}$ dates (Figure 3). The other date is from Gyodong dwelling pit 1, measured on wood charcoal, and giving a very old date (Baek et al. 2002), but, as shown above, the date of the charred rice is much younger (Figure 3). Considering the certainty of association with the dwelling itself, the younger dates appear to be more reliable. On the other hand, the timing of the adoption of rice agriculture in the Japanese islands is known primarily through dating charred remains on pottery. Since it could be younger than 10th century BC as shown above, there is a certain time lag in wet rice adoption between South Korea and Japan. This means that the adoption of rice agriculture in these 2 areas was possibly brought about by different climatic circumstances or social contexts in northeast Asia.

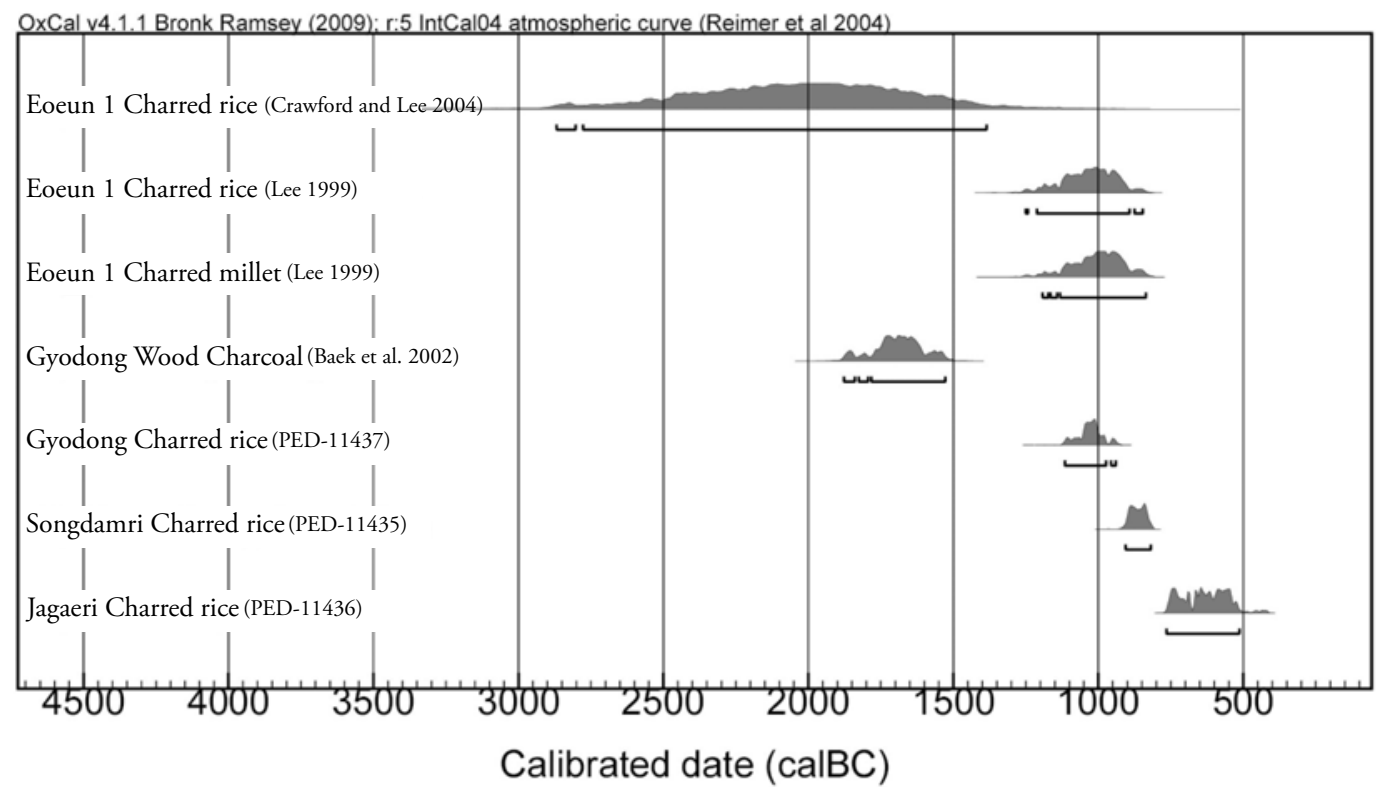

Figure 3 Calibrated dates of charred rice, millet, and wood charcoal samples from Bronze Age Korea. Calibration done using OxCal v 4.1.1 (Bronk Ramsey 1995, 2001) and the IntCal04 data of Reimer et al. (2004).

The adoption of metal in the Korean peninsula did not occur at the very beginning of the Early Bronze Age. However, very little ${ }^{14} \mathrm{C}$ data are directly related to bronze samples, making it difficult to know the absolute date of bronze adoption. Even though its chronology is still unclear, Park (1993) argued that it appears approximately from the end of the 2nd to the first part of the 1st millennium BC. On the other hand, with regard to metal adoption in the Japanese islands, it was traditionally thought that an influx of iron preceded bronze, based on the iron tools found at the Magarita and Saitoyama sites, which had been considered to date to the Initial Yayoi (Otomasu 1981; Hashiguchi 1984). However, as a byproduct of this Yayoi dating controversy, when reexamined, these examples were found to have poor archaeological contexts and can now be considered to be younger. Following the reexamination by Nojima (2008), the beginning of the iron influx into the Japanese islands can be pushed later to the beginning of the Middle Yayoi. Accordingly, the intro- 
duction of bronze, which started in the early part of the Early Yayoi, seems to precede that of iron, which is contrary to the traditional understanding of metal introduction to Japan (Hashiguchi 1984).

Moreover, and most importantly, this controversy has paved the way to connect the archaeological chronology with ${ }^{14} \mathrm{C}$-based natural history, such as climate change or vegetative transition. New dates show that the beginning of the Yayoi, including the introduction of irrigated wet rice agriculture, precedes the global cold period in the middle of 1st millennium BC, which is also recorded in the cedar tree rings of Japan (Sakurai et al. 2006). Therefore, the conventional explanation for the Jomon/Yayoi transition based on a deteriorating economy in western Japan or refugee immigration from the continent caused by climatic cooling (Fujio and Imamura 2009) is either not correct or the transition did not occur simply because of climate change. Comparative study between archaeological materials and environmental history is fairly well underway to reveal in which circumstances people drastically changed their subsistence strategies both in Japan and Korea.

\section{CONCLUSION}

A broad strategy of using AMS ${ }^{14} \mathrm{C}$ dating led Japanese archaeologists to rethink the traditional dating of the 1st millennium BC. The beginning of the Yayoi period has been pushed back by several hundred years, though there are still varying opinions concerning the exact date. As the chronology in northeast China is connected to the written record of the central plain of China, it does not change because of ${ }^{14} \mathrm{C}$ dating. Thus, a reexamination of the chronology in the intermediate Korean peninsula was required and attempted. Although recently an enormous number of ${ }^{14} \mathrm{C}$ dates have been accumulated by Korean archaeologists, the chronology itself is in dispute, partly because so many of the ${ }^{14} \mathrm{C}$ dates have no clear archaeological contexts. Yet, by combining the typological studies and initial AMS ${ }^{14} \mathrm{C}$ dating for charred rice grains we can postulate an interim absolute dating of the adoption of rice agriculture both in South Korea ( 12th/11th century BC) and Japan ( 9th/8th century BC). As a result, there appears to be a clear time lag in wet rice adoption between these areas. This dating will help to improve the study of archaeological materials by correlating them with environmental studies, to develop new ideas about why people changed their subsistence strategies to adopt rice agriculture, thus triggering prehistoric social change in both areas.

\section{ACKNOWLEDGMENTS}

I want to thank Ahn Sungmo, Na Geonju, Son Joonho, Lee Seongju, Sugiyama Shinji, Nasu Hiroo, Takigami Mai, Catherine Frieman, and Paleo Labo Co. Ltd for helping with this study. Also, thanks to everyone who gave me useful comments at the conference. This study is supported by the Japan Society for the Promotion of Science (No. 19-1973).

\section{REFERENCES}

Bae JS. 2007. Formation of Mumun Pottery Culture and Social Classification. Seoul: Seogyong. 263 p. In Korean.

Baek HK, Ji HB, Park YK. 2002. Dwelling Sites in Gyodong, Kangnung. Kangnung: Museum of Kangnung National University. 200 p. In Korean.

Bronk Ramsey C. 1995. Radiocarbon calibration and analysis of stratigraphy: the OxCal program. Radiocarbon 37(2):425-30.

Bronk Ramsey C. 2001. Development of the radiocarbon calibration program. Radiocarbon 43(2A):355-63.

Crawford G, Lee GA. 2003. Agricultural origin in the Korean peninsula. Antiquity 77(295):87-95.
Fujio S. 2007. The beginning date of Yayoi period. In: Nishimoto T, editor. From Jomon Period to Yayoi Period. Tokyo: Yuzankaku. p 7-19. In Japanese.

Fujio S, Imamura M. 2009. Environmental change in the beginning of Yayoi period based on the carbon-14 record. In: Shitara H, Fujio S, Matsugi T, editors. Archaeology of Yayoi Period 2. Tokyo: Douseisha. p 172-87. In Japanese.

FukasawaY, Shoda S. 2009. Seon Songgukri /Songukri type pottery and Yusu Itazuke type pottery. In: Shitara H, Fujio S, Matsugi T, editors. Archaeology of Yayoi Period 2. Tokyo: Douseisha. p 172-87. In Japanese.

Harunari H, Fujio S, Imamura M, Sakamoto M. 2003. 
Yayoi Jidai no Kasishi Nendai (The beginning date of the Yayoi period). Abstracts for the 69th Annual Meeting of the Japanese Archaeological Association. p 658. In Japanese.

Hashiguchi T. 1984. Iron tools. Ishizaki Magarita Site II. p 423. Fukuoka: Education Board of Fukuoka Prefecture. In Japanese.

Kim JS. 2001. Rethinking Hunamri assemblage. Yeonnam Kokohak 28. In Korean.

Korean Institute for Archaeology and Environment. 2008. Information Packet for On-site Explanatory Meeting on the Excavation of the Site for MACCA. In Korean.

Lee BK. 1974. Mumun pottery and polished stool tools in Geyongi-do. Archaeology 3:53-130. In Korean.

Lee HW. 2009. Settlement Structure and Social Organization in the Bronze Age. Seoul: Seogyong. 292 p. In Korean.

Lee SK. 1999. Outline of the excavation on Jinju Daepyong Eoeun loc.1 site. Seminar on the Prehistoric Remains of the Nam River. Busan: Dong-a University Museum. p 103-10. In Korean.

Miyaji S. 2009. Typological reconsideration of pottery samples for radiocarbon dating at the beginning of Yayoi period. Quarterly of Archaeological Studies 55(4):35-54. In Japanese.

Mizunoe K. 2009. Reexamination of Kurokawa type pottery. In: Nishimoto T, editor. The Beginning of Yayoi Agriculture and Its Dating. Tokyo: Yuzankaku. p 11427. In Japanese.

Na GJ. 2006. Report on the Excavation of Jagae-ri Site (I), Dangjin. Gongju: Chungcheong Cultural Properties Research Institute. In Korean.

Nishimoto T. 2007. From Jomon culture to Yayoi culture. In: Nishimoto T, editor. From Jomon Period to Yayoi Period. Tokyo: Yuzankaku. p 3-6. In Japanese.

Nojima H. 2008. Studies of the Introduction and Circulation of Early Iron in Yayoi Period. Hiroshima: Hiroshima University. 128 p. In Japanese.

Onuki S. 2003. Orthodoxy and heresy. In: Kokogaku Kenkyukai Tokyo Branch 4th Meeting Abstracts. Tokyo. p 37-46. In Japanese.

Otomasu S. 1981. Saitoyama site. In: The Japan Archaeologists Association, editor. The Origin and Growth of Farming Community in Japan. Tokyo: Tokyodo. p 5131. In Japanese.
Park SB. 1993. Bronze and Iron culture in the Han River Basin. In: The History of Han River Basin. Seoul: Mineunsa. p 115-223. In Korean.

Park SB. 1999. Investigation on formation of Hunam-Ri Assemblage. Journal of the Hoseo Archaeological Society 1:79-93. In Korean.

Reimer PJ, Baillie MGL, Bard E, Bayliss A, Beck JW, Bertrand CJH, Blackwell PG, Buck CE, Burr GS, Cutler KB, Damon PE, Edwards RL, Fairbanks RG, Friedrich M, Guilderson TP, Hogg AG, Hughen KA, Kromer B, McCormac G, Manning S, Bronk Ramsey C, Reimer RW, Remmele S, Southon JR, Stuiver M, Talamo S, Taylor FW, van der Plicht J, Weyhenmeyer CE. 2004. IntCal04 terrestrial radiocarbon age calibration, 0-26 cal kyr BP. Radiocarbon 46(3):102958.

Renfrew C. 1973. Before Civilization. London: Jonathan Cape. 320 p.

Sahara M. 1975. Beginning of agriculture and formation of class society. In: Japanese History 1. Tokyo: Iwanami Shoten. p 113-82. In Japanese.

Sahara M. 1981. Natural scientists as seen by an archaeologist. In: Mabuchi H, Tominaga T, editors. 10 Chapters on Chemistry for Archaeology. Tokyo: University of Tokyo Press. p 1-24. In Japanese.

Sakurai H, Kato W, Takahashi Y, Suzuki K, Takahashi Y, Gunji S, Tokanai F. 2006. ${ }^{14} \mathrm{C}$ dating of $\sim 2500$-yr-old Choukai Jindai cedar tree rings from Japan using highly accurate LSC measurement. Radiocarbon 48(3):401-8.

Shoda S. 2006 A bronze dagger from Birae-dong and the dating of the Yayoi period (II). Kodai 119:123-58. In Japanese.

Shoda S. 2007. A comment on the Yayoi period dating controversy. Bulletin of the Society for East Asian Archaeology 1:1-7.

Shoda S. 2009a. Production and Society in the Southern Korean Bronze Age. Seoul: Hakyoun Cultural Publishing. 304 p. In Korean.

Shoda S. 2009b. A chronological study of Korean Bronze Age. Journal of the Archaeological Society of Nippon 93(1):1-31.

Xia-Shang-Zhou Dating Project Group. 2000. Report of Xia-Shang-Zhou Dating Project, 1996-2000. Beijing: Shijie Tushu Publishing. 118 p. In Chinese. 